\title{
Small Bowel Internal Herniation through Acquired Defect of Vesicouterine Pouch- A Late Complication following Oophorectomy
}

Thayalan Rao Appalasamy ( $\sim$ thayalan0487@gmail.com )

National University of Malaysia Faculty of Medicine: Universiti Kebangsaan Malaysia Fakulti Perubatan https://orcid.org/0000-0003-2204-1973

Fahrol Fahmy

National University of Malaysia Faculty of Medicine: Universiti Kebangsaan Malaysia Fakulti Perubatan

Tan Jih Huei

Hospital Sultanah Aminah

Aina Shafiza

Hospital Sultanah Aminah

Tuan Nur Azmah

Hospital Sultanah Aminah

\section{Research Article}

Keywords: Viscus herniation, vesicouterine pouch, gynaecology surgery, laparotomy

Posted Date: January 13th, 2022

DOl: https://doi.org/10.21203/rs.3.rs-227435/v1

License: (c) (1) This work is licensed under a Creative Commons Attribution 4.0 International License.

Read Full License 


\section{Abstract}

Hollow viscus herniation through a defect between vesicouterine pouch following previous pelvis surgery is exceedingly rare. There was only 1 similar case reported in the English literature. In this current report, we describe a 84-year-old woman presented with lower abdominal pain. She had a history of previous gynecology surgery. Computed tomography of abdomen showed small bowel obstruction with transition zone at the pelvis. Laparotomy revealed small bowel loops trapped in the vesico-uterine space via a narrow defect about $1.5 \mathrm{~cm}$. The detailed clinical summary and operative management are described in the report.

\section{Introduction}

Internal hernias are defined by the extension of viscus through normal or abnormal apertures within the peritoneal cavity. Internal hernias can be divided into congenital or acquired hernias. Acquired cases of internal hernias are mostly iatrogenic secondary to surgically created defects in the mesentery and adhesions from prior surgical interventions. Internal hernias are the cause of $0.6-5.8 \%$ of cases of small bowel obstruction (SBO). In general, the preoperative diagnosis of an internal hernia is difficult. Unlike ventral and inguinal hernias, no physical protrusion can be appreciated on the abdominal exam. The pelvis has spaces that may lead to herniation. A gynecological surgery may cause internal hernia, more commonly reported as pouch of douglas (POD) hernia. From previous literature, we identify only 1 case with vesicouterine pouch small bowel herniation following oophorectomy in a middle age lady[1]. In this report, we describe a similar case of an elderly lady presented with small bowel obstruction after ten years of previous oophorectomy. We performed a differing surgical management in contrast to previous reported case. The detail of the case and justification of operative management will be elaborated and discussed in the report.

\section{Case Report}

A 84-year-old woman presented with lower abdominal pain for 5 days. She had history of reduced stool output. She had previous bilateral oophorectomy for a benign ovarian tumor done more than 10 years ago. On physical examination, she had mild tenderness in the lower abdomen with a healed pfannenstiel scar. Abdominal radiographs showed single sentinel small bowel loop dilatation. Abdominal computed tomography (CT) scan revealed small bowel obstruction with transitional zone in pelvis. She did not improve following initial conservative approach, hence an emergent laparotomy was performed.

Intraoperatively, there was adhesion between omentum to the previous scar at lower abdomen. A $15 \mathrm{~cm}$ loop of small bowel at $200 \mathrm{~cm}$ from duodeno-jejunal flexure was trapped in the vesicouterine space via a narrow defect about $1.5 \mathrm{~cm}$. Upon reduction, the trapped small bowel about $10 \mathrm{~cm}$ appeared non-viable. The gangrenous small bowel was resected and primary end-to-end anastomosis done. The adhesion formed between uterus and bladder causing the peritoneal defect was laid open to prevent recurrence of such internal herniation. Following complete release, the peritoneal cavity communicates freely to the space. Postoperatively, she was extubated and put on nasal prong 3liter per min due to atelectasis. She 
recovered well following 8 days of stay. Follow-up review in 2 months' time, she remained well with no recurrence.

\section{Discussion}

Pelvis hernia is uncommon. It may develop following gynaecological surgery. Pouch of douglas (POD) hernia is one of its form which are more commonly reported in female with previous gynecological surgery[2]. In contrary, we report another rarer form of pelvis hernia following previous oophorectomy. The previous case was reported in a middle age lady where laparoscopic approach was performed[1]. The authors attempt to repair the hernia defect. However, in current case we did not repair the defect. Instead we release the adhesion between the uterus and bladder. Following the release of adhesion, it was a large space communicating freely to the peritoneal cavity. We placed the small bowel safely posterior to the uterus and omentum. The patient did not have any recurrence on follow up.

Taking the literature from POD hernia, the definitive operations were open primary closure, laparoscopic reduction and prosthetic repair at preperitoneal plane. There weren't any of similar operative approach as current reported case. The justification from previous literature for closing the defect as it is thought that the POD hernia occurred due to rent in the peritoneum[2] [3]. In contrary to current case, a vesicouterine hernia is due to deficient in the adhesion membrane[1].

Another interesting point to note in this case is failure to diagnose the cause of small bowel obstruction preoperatively. Due to extensive small bowel dilatation, it often difficult to clinch the etiology on CT. A previous report encourages the use of both frontal and transverse CT images to diagnose internal hernia. [4] Similarly in this case, the CT images were clinched to the diagnosis only following the surgery with rereviewed images on sagittal and axial. If the diagnosis of internal herniation was made early, the interval for conservation and subsequent bowel resection may had been avoided.

\section{Conclusion}

It is important to consider internal hernia through pelvic peritoneal defects as part of the differential in patients who present with a small bowel obstruction especially with previous history of gynaecologic surgery. Following oophorectomy or a gynaecologic surgery, a late presentation of small bowel obstruction may result from an internal herniation through vesicouterine pouch. The definitive surgical choice to repair or not to repair is yet to be conclusively cleared with current evidence. Its definitive operative steps shall be individualized; however, a systematic review of such rare entity shall be looked forward. CT imaging with multiplanar viewing are essential to clinch this pathology early to prevent morbidity of needing bowel resection.

\section{Declarations}

\section{Funding}




\section{Conflicts of Interest}

The authors declare that no competing interests.

\section{Ethics Approval and Consent to Participate}

This case report is in line with the local ethics protocol and all the photographs and records included have obtained patient consent, whichever applicable. The records, radiographs and images were the property of the institution and local approval has been obtained for both retrieval and publication.

\section{Consent for Publication}

The written consent was obtained from the patient including publication of the case details and associated images.

\section{Data Availability}

Not applicable.

\section{Authors' Contributions}

All the authors included are sequenced in accordance with the contribution of each. Thayalan Rao Appalasamy were involved in the conception of report idea, Thayalan Rao Appalasamy had acquired and summarized the patient case and together with Tan Jih Huei, was the major contributor of the literature review and the write up of the manuscript. Aina Shafiza and Fahrol Fahmy, Tuan Nur Azmah were involved in the revision of the manuscript and final write up. All the authors read and approved the final manuscript.

\section{References}

1. Sakamoto T, Kawarai Lefor A, "Laparoscopic Reduction and Closure of an Internal Hernia Secondary to Gynecologic Surgery," Case Rep Surg, vol. 2017, 2017, doi: 10.1155/2017/5948962.

2. Muthukumar V, Venugopal S, Subramaniam SK. Report of a case and review of literature of internal hernia through peritoneal defect in pouch of douglas: A rare occurrence. International Journal of Applied Basic Medical Research. Jul. 2017;7(3):196. doi:10.4103/ijabmr.IJABMR_297_16. 
3. Suwa K, Yamagata T, Hanyu K, Suzuki T, Okamoto T, Yanaga K. Internal hernia through a peritoneal defect in the pouch of Douglas: Report of a case. Int J Surg Case Rep. Oct. 2012;4(1):115-7. doi:10.1016/j.ijscr.2012.10.015.

4. Yoshida $T$, et al. Bowel obstruction caused by an internal hernia that developed after laparoscopic subtotal colectomy: a case report. J Med Case Rep. Dec. 2014;8(1):470. doi:10.1186/1752-1947-8470 .

5. Wang E, Humphries A, Johnson LS, "Small bowel obstruction due to internal hernia through sigmoid epiploica," Journal of Surgical Case Reports, vol. 2019, no. rjy342, Jan. 2019, doi: $10.1093 /$ jscr/rjy342.

\section{Table}

Table 1

Review of similar cases

\begin{tabular}{|llll|}
\hline $\begin{array}{l}\text { Author and } \\
\text { year of } \\
\text { report }\end{array}$ & $\begin{array}{l}\text { Age and } \\
\text { Gender }\end{array}$ & Presentation or history & Surgical Management \\
\hline $\begin{array}{l}\text { Takashi } \\
\text { Sakamoto } \\
{[1]}\end{array}$ & $\begin{array}{l}49 \text { years } \\
\text { old, } \\
\text { female }\end{array}$ & $\begin{array}{l}\text { Presented with pain, underwent open right } \\
\text { unilateral oophorectomy for a benign ovarian } \\
\text { cyst }\end{array}$ & $\begin{array}{l}\text { Laparoscopic } \\
\text { reduction and primary } \\
\text { clsoure }\end{array}$ \\
\hline $\begin{array}{l}\text { Eugene } \\
\text { Wang [5] years }\end{array}$ & $\begin{array}{l}\text { Presented with pain, underwent Caesarean } \\
\text { old, } \\
\text { female }\end{array}$ & $\begin{array}{l}\text { Section } \\
\text { Laparotomy and } \\
\text { primary reduction of } \\
\text { hernia }\end{array}$ \\
\hline
\end{tabular}

\section{Figures}




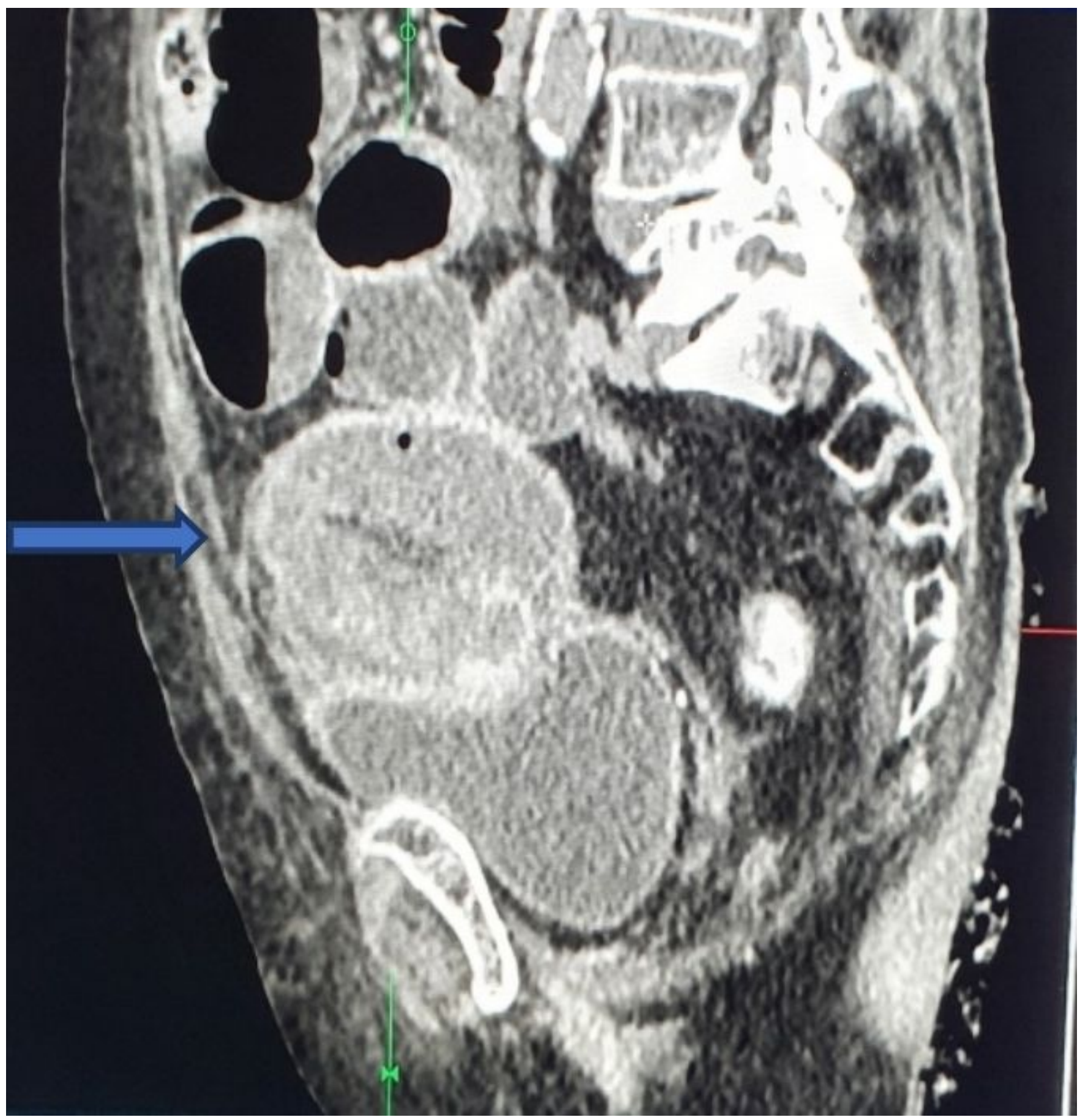

Figure 1

(sagital view) : Arrow pointing to the sharp transition point 


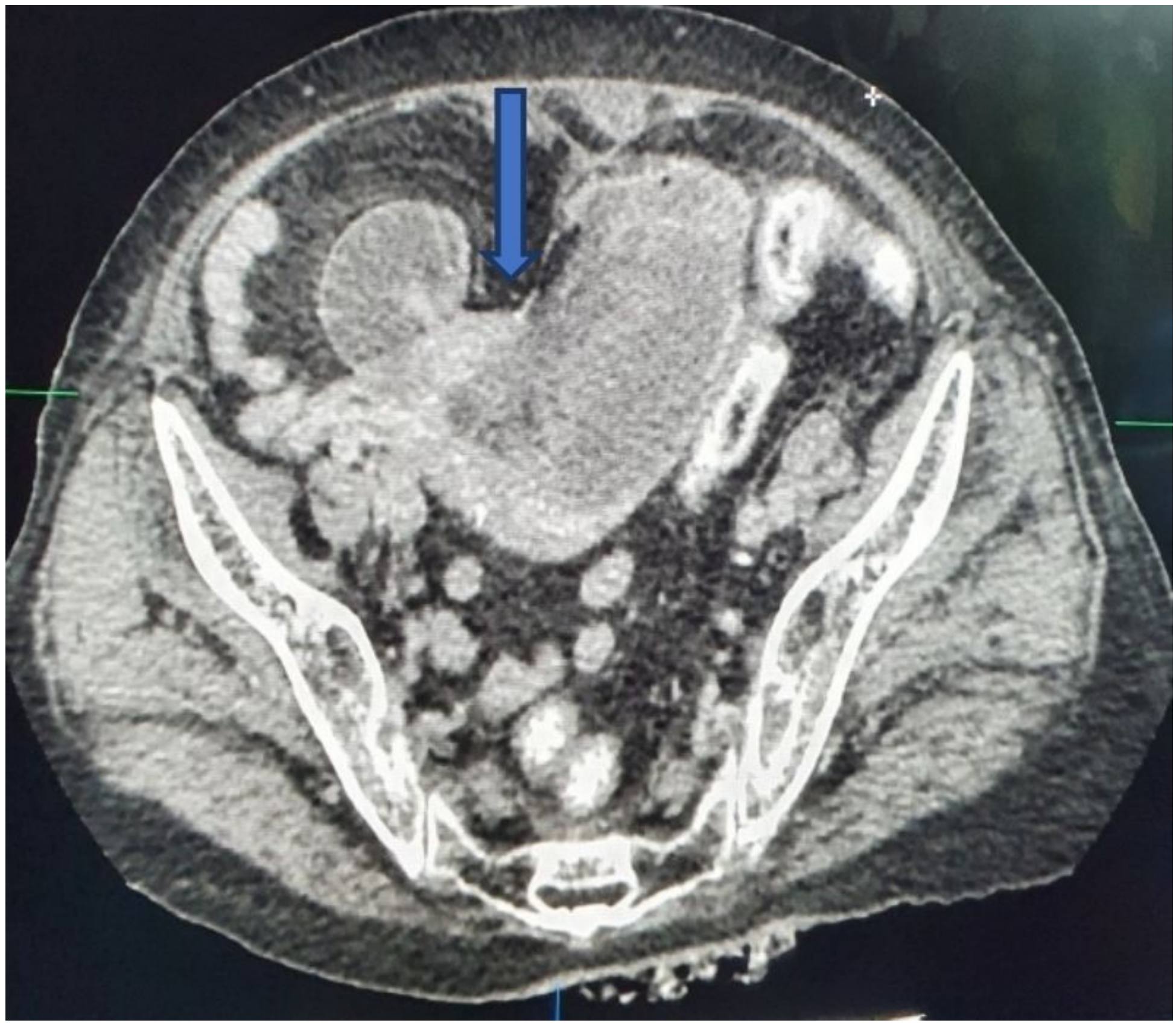

Figure 2

(axial view) : Arrow pointing dilated small bowel in the transitional zone (pelvis) 


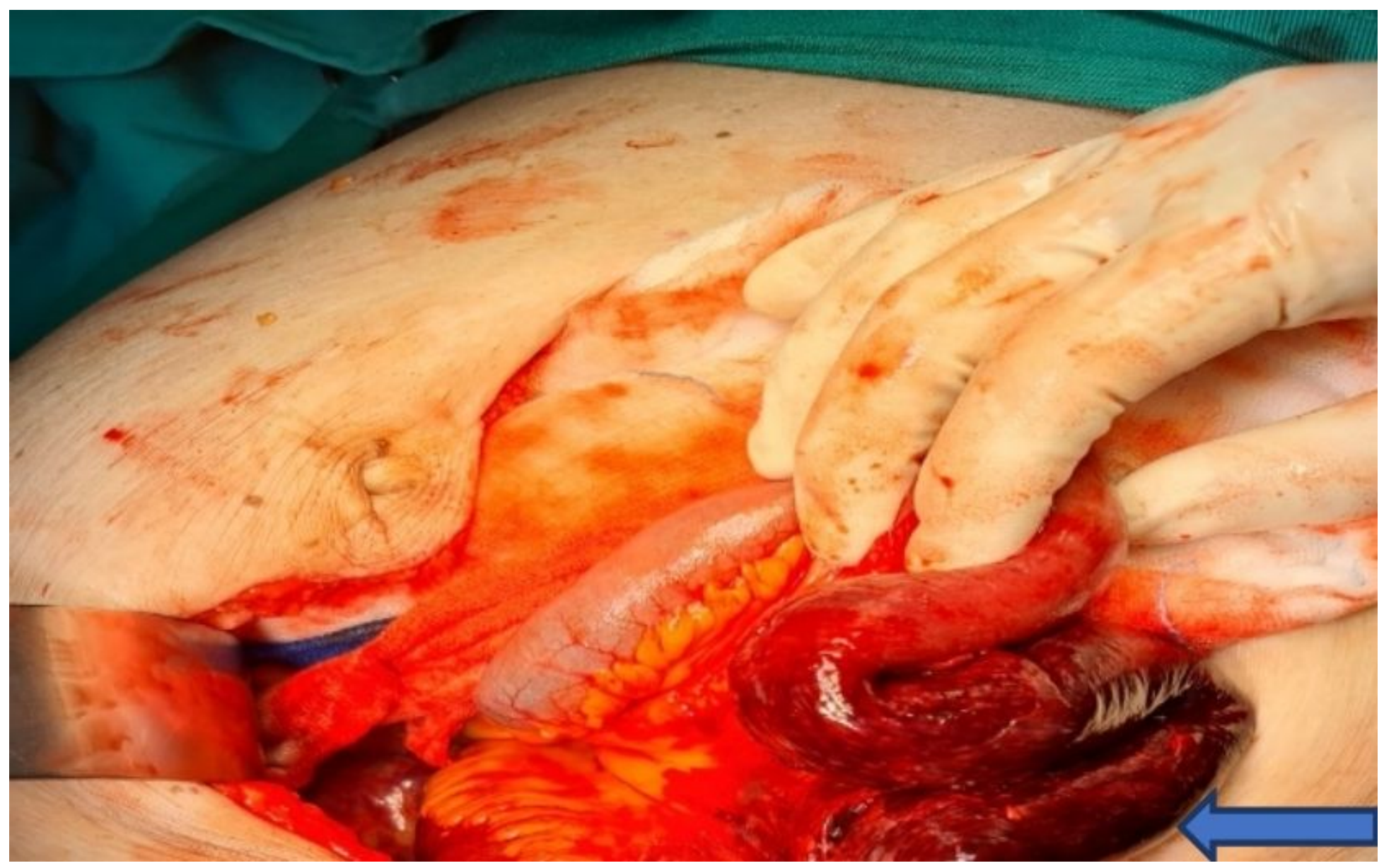

Figure 3

Gangrenous- looking short segment small bowel 


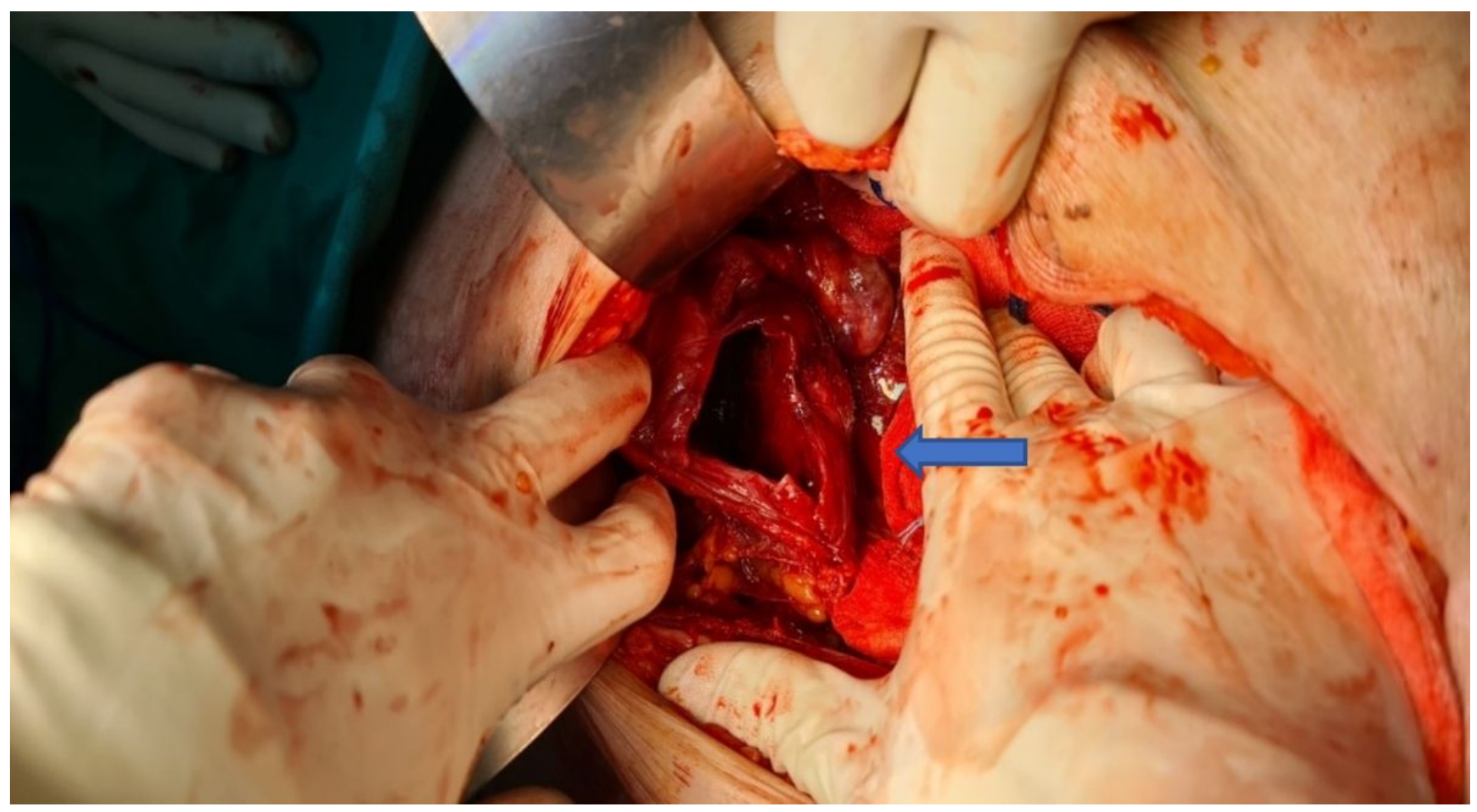

\section{Figure 4}

Pelvic hernia defect arising from vesico-uterine pouch partially released

\section{Supplementary Files}

This is a list of supplementary files associated with this preprint. Click to download.

- CAREchecklist.pdf 